\title{
Effects of Tourism on Handicrafts Industry Development During the Process of Recovering from the Earthquake in Beichuan, China
}

\author{
Chuntao $\mathrm{Wu}^{1}$, Mai Xianmin ${ }^{2 *}$, Tingting Yuan ${ }^{1}$, JingTing Yuan ${ }^{1}$ \\ ${ }^{1}$ School of tourism, Sichuan University, P.R. China \\ ${ }^{2}$ School of Urban Planning \& Architecture, Southwest Minzu University, P.R.China \\ E-mail: maixianmin@foxmail.com
}

\begin{abstract}
This paper studies the effects of tourism development on innovation and diversification of ethnic handicrafts in a newly development natural disaster tourism site - Beichuan Qiang Tourism Area in Sichuan, China. Beichuan was one of the worst-affected regions during the Great Sichuan Earthquake of May 12, 2008. Fieldworks including site visit, participation and observation, semi-structure interview with the local elites and tourists' questionnaire survey are methods used by this paper. The results indicate that tourism development has leaded to a diversity of the embroidery handicrafts and is re-shaping the embroidery industries now. It is argued that local Qiang embroidery enterprises should decrease the cost and tailor the products to increase the sales. The higher quality and authenticity of embroiders' product should be emphasized so that tourists can see the reason for the higher price of the local hand-made products.
\end{abstract}

KeyWords: Earthquake recovering; Beichuan; Qiang Embroidery; natural disaster destination management

\section{Introduction}

Beichuan Qiang Autonomous County located in the northwestern Sichuan Basin of China is the worst-hit area of the Great Sichuan Earthquake of May 12, 2008. As the hardest hit area in the earthquake, Beichuan County had a casualty of 15645 and 1023 missing. It is estimated that the direct economic losses resulted from the earthquake in Beichuan amount to as much as 58.6 billion RMB (US $\$ 9.4$ billion); various buildings, facilities and infrastructures were completely were destroyed. Qushan Town (here after Beichuan old town), the economic, political and cultural center of the Beichuan County, was razed to the ground immediately. After the earthquake, the State Council built a new center of Beichuan Country (hereafter Beichuan new town) about 23 kilometers away from the old Town. It was emphasized that the new town should be the milestone in civil construction, the sign of the earthquake relief spirit, the symbol of the Qiang ethnic culture.

According to Regulations on Reconstruction in Wenchuan published by State Council, tourist industry is recognized as competitive and leading industry during the process of recovering. Consequently, local government built a new scenic spot - Beichuan Qiang Tourist Area. Covering an area of 60 square kilometers, the Beichuan Qiang Tourism Area consists of the old town and the new town. The main attractions in the old town are earthquake ruins, Tangjiashan Brrier Lake and Wenchuan Earthquake Museum. The government preserved the whole old town as the largest urban earthquake ruins in the world; and built an Earthquake Museum near the ruins. Meanwhile, the hotels, restaurants, Qiang ethnic minority style museums, buildings and shopping streets are located in the new town. The Qiang Tourist Area totally received more than 6.29 million tourists during the period 2010-2013, and was named as the National AAAAA Scenic Spot (the top level Scenic Spot of China) in 2013. It means that Beichuan had become the paradigm of the successful natural disaster dark tourism site.

One other hand, the government has been subsidizing Qiang embroidery industry and promoting cultural preservation in this area. For example, the government advocated many Qiang embroidery projects to create job positions for Qiang women. Before the earthquake, however, the Beichuan' traditional Qiang embroidery industry was less developed. It was reflected by that there were only a few kinds of Qiang embroidery products in Beichuan. It was also reflected by that the embroidery artisans mainly lived in Mao country, Li country or other places located in Sichuan Aba Qiang Autonomous 
Prefecture. Thus, two interesting questions were raised. (1) To which extent that tourism could promote embroidery industry in a disaster destination? (2) Could the ethnic culture create a new image for a disaster tourism destination?

The study purpose of this paper is to analyze the impact of tourism development on the embroidery handicraft sector during the recovering period, and to interpret the potential effects of ethnic culture elements on building Beichuan a new image. The study focuses on the Qiang embroidery handicrafts. It is partly due to that the textile crafts is the most symbolic tourist souvenir (Littrell, 1990). It is also partly due to city planners have been trying to build Beichuan a bright image, by using Qiang embroidery elements to design city logo. The research results can give destination managers and policy makers some practical suggestions about disaster destination construction. The result also contributes to the natural disasters tourism theory.

\section{$2 \quad$ Literature Review}

Natural disaster tourism is an activity to visit sites associated with dead or tragic events caused by natural disaster such as earthquake, typhoon, tsunami, debris flow, or volcanic (Funck, 2014). The natural disaster tourism is one kind of dark tourism which refers to an act of travel to sites associated with death, suffering and the seemingly macabre (Stone, 2006). Over the last decade, many researchers have studies the management and interpretation of dark sites related to war, death camp, prison or slave (e.g. Strange et al, 2003; White, 2009; Biran et al., 2011, Wu et. al., 2014). As a postmodern phenomenon, the dark tourism combines elements of education and commodification (Lennon and Foley, 2000). However, the promotion of dark tourism may raise intense controversies about preservation and interpretation, as the dark tourism always connected to the darker side of humanity (Hartmann, 2012). Less attention, however, has been paid to the sites of natural disaster.

Taking the Great Hansin-Awaji Earthquake as an example, Funck (2014) founded that the areas experienced large-scale natural disasters played an important role in educational tourism. After the earthquake reconstruction, the tourism industry provides a necessary platform for victims to convey the earthquake experience and public memory. She argued that "dark" is not an adequate term to describe the disaster site. Firstly, the interpretation of the disaster site is less contested. Such as in Japan, the interpretations and messages strongly emphasized the positive influences such as smooth reconstruction, mutual help or human resilience, but neglected the conflicts during the reconstruction process. The reasons are: (1) the mass media and public always show sympathy for victim; and (2) different personality, social state, influence, impact, resilience and recoverying experience brought the victim different memories.

Based on the previous studies, this study investigates possibly effects of tourism on other industries in the disaster site. The study also explores the effects of culture elements on (re)branding or (re)building destination a lighter image. It is an important issue for host community, as the local people always view dark tourism as an unwanted disruption of their living space (Seaton, 2009) and eager to build a new image (Wu et. al., 2014). It is also an important issue in China, as the tourism is placed high expectation to help the handicraft industry in indigenous area (Xu et. al., 2014). Researchers have measured economic impact of devastating Wenchuan 5.12 earthquakes on Sichuan tourist industry (e.g. Yang 2011), but hardly paid attention to the actual impacts of tourism on other industries during the reconstruction process.

This paper studies the handicraft industry in the disaster area. Souvenir is a salient part of the modern industry, and handicraft souvenir is an important sector in indigenous tourism (Smith, 2009). Over the last four decades, scholars and researches have studied the tourism souvenir in various aspects, such as authenticity, commodification, consumer behavior, craft production, economic development, cultural property rights, gift-giving, shopping, retail, souvenir messages or meanings (see Swanson \& Timothy, 2012). Focusing on the indigenous handicraft, researchers have carried out a comprehensive study on the effect of tourism on handicraft industries. Such as Cohen (1993) argued that tourism development facilitated the spread and innovation of handicrafts; Xu (2014) founded that tourism development had led to an innovation and diversification of traditional ethic handicraft such as silver handicraft in China. Again, less attention has been paid to the disaster site. 


\section{Methodology}

Figure 1 shows the research frame of this paper. Firstly, fieldwork including site visits, participation and observations were carried out to classify the current embroidery products in Beichuan Qiang Tourist Areas based on five indicators: price, usage, material used, pattern, and mass-produced item or handmade item. Swanson (2004) divided souvenirs into two items: mass-produced item and handmade item according to the producer. The former produced by manufacturers are tend to be cheaper and of more consistent quality. Oppositely, the handmade ones made by craftspeople are more expensive but have greater opportunity to be customizable and unique.

Secondly, semi-structured interviews were conducted with 12 elites, including local labor, women or tourism officers, owners and employees of all embroidery manufacturers. The interviews were conducted in February and March, 2014. In each interview, elite was required to answer three questions. (1) Compared with pre-earthquake state, what changes happened to design, composition and category of Qiang embroidery handicrafts? (2) What changes happened in production processes? (3) To what extent that tourism industries have impacted the embroidery handicraft industry?

Thirdly, tourist' questionnaire survey was conducted to investigate the value of embroidery and the effect of Qiang culture on image of Beichuan. The questionnaire survey was conducted in March 2014, in front of Beichuan Former County Relic (Earthquake Museum and Earthquake Relic) and Banaqia Shopping Street. 180 questionnaires were distributed and 164 effective responses were collected. The questionnaire includes the questions about characteristics of respondents, motivation and their perception of visitors on Qiang embroidery and the image of Beichuan.

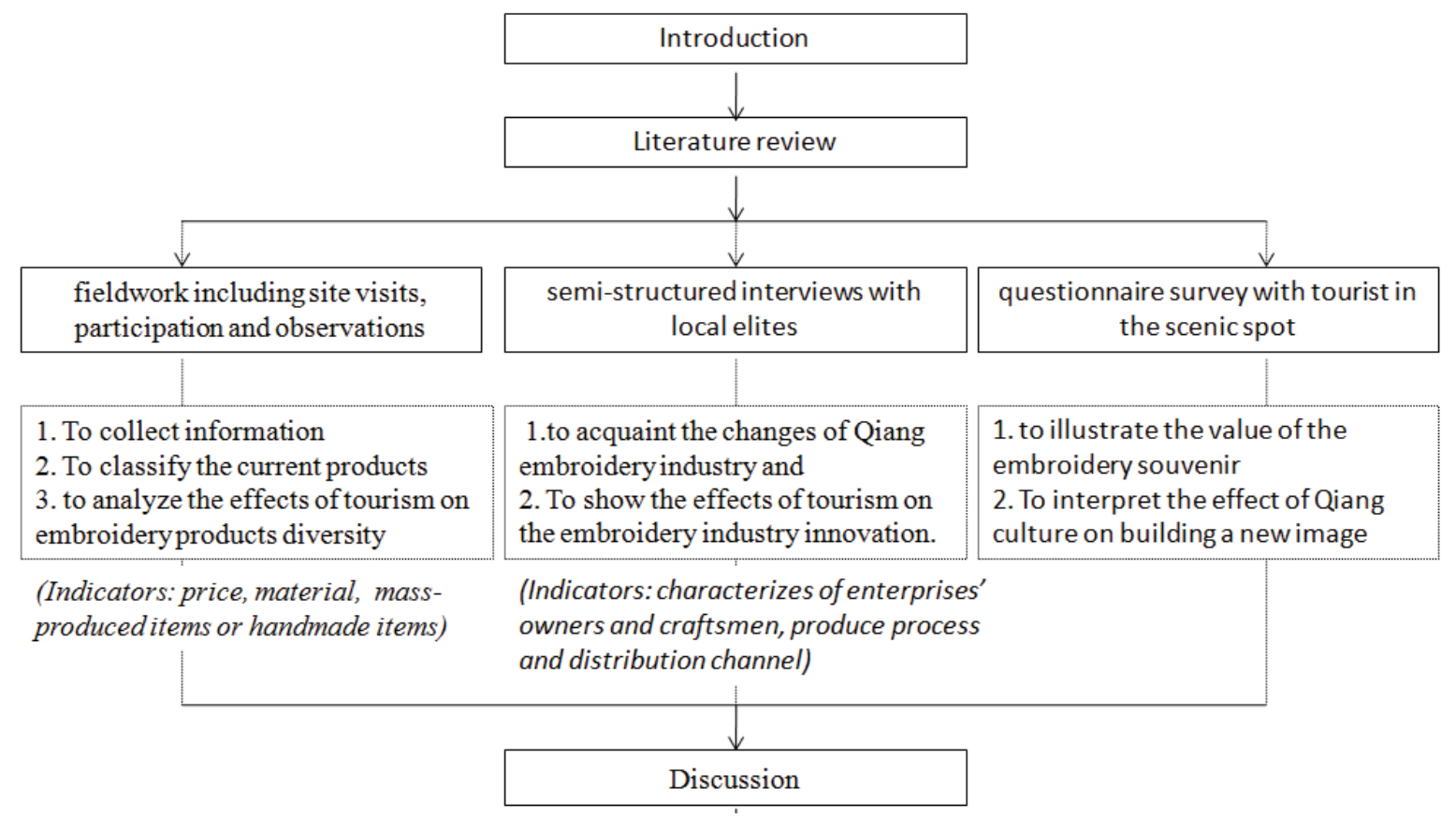

Figure 1. Research frame

\section{Evolution of Qiang Embroidery Handicrafts after the Earthquake}

\subsection{Changes of Qiang Embroidery Handicrafts Products}

Qiang embroidery is a traditional artistic creation for spontaneous and self-entertainment. 

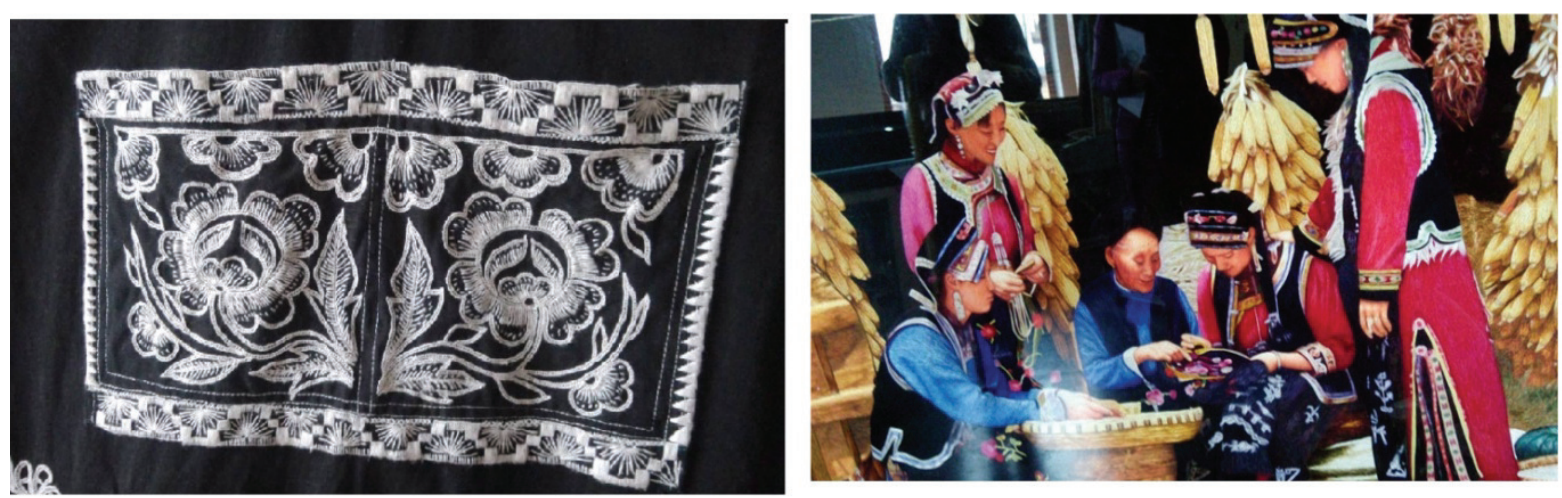

Source: Beichuan Xiuniang

Figure 2. Traditional Qiang embroidery handicraft (left) and model embroidery handicraft

According to figures springing to mind, Qiang women design and prick out the pattern on the cloth simultaneously. Traditional Qiang embroidery crafts are characterized by black lines and white (or blue) background (see Figure 2, left). Cotton thread, linen thread and yarn are frequently-used thread. Embroidery cloth used to be black, blue or white cotton fabric. The embroidery is used to design clothes, bags, purses, insoles and other practical items. Figures were always embroidered on parts where easy to be worn since the dense stitches would made clothes more wear-resisting. Design patterns are always about daily lift of Qiang people, natural scenes, flower, leaf, and animals like goat, deer, lion, bird and insect. Being limited by techniques and thread, the Qiang women could not create pattern such as themed portrait or truly depiction.

Over those six years, the tourism has stimulated the local handicrafts industry development and led to an innovation of the traditional crafts. Significant changes happened to composition, thread, techniques and frame of the embroidery in Beichuan (Figure 2, right). According to the price, usage, material used, pattern, and mass-produced item or handmade item, embroidery products can be divided into four categories currently: innovated product, improved product, common product and cheaper product.

1. Innovated product: priced 2,000-500,000 RMB. Professional designers decide theme, backer and colors. The product is completed by several embroiderers, combing techniques and materials of Suzhou embroidery. The main forms are wall hangings and screens. and main themes are Earthquake relief, state leaders' portraits, pictures of Qiang daily life.

2. Improved product: priced 400 to 2,000RMB. The main forms are wall hangings, various scarves and bags decorated by embroidery pattern. Designers select raw materials and patterns. A skillful embroidery girl could complete one embroiderer within a week or so.

3. Common product: priced 100 to 400RMB. The main forms are insoles, purses, sachet and hangings with a little Qiang embroidery decoration. The product could be is completed by one embroiderer within three days. The price is relative to work time.

4. Cheaper product: priced 30 to 100RMB. The product is mass-produced item made by machines. Vendors bought it from wholesaled and sold to tourists in every scenic spots.

\subsection{Development of Qiang Embroidery Industry}

It is believed that the embroidery industry can generate income with low barrier to entry, simplifying women involvement and integrating their household duties in disaster area. Such as a famous NGO - One Foundations had set up a project specifically, aiming to encourage Qiang women in disaster areas to help themselves by engaging in product Qiang embroidery crafts in Aba Qiang Autonomous, Sichuan Prefecture. After the earthquake, Beichuan Government built a modern embroidery industrial Park and advocated a women job promotion scheme depending on the embroidery industry. Gradually, many outside skilled artisans move to the new town and formed a Qiang embroidery industry cluster nearby the tourist area. 
Nowadays, Beichuan Qiang embroidery crafts are produced by three private enterprises: Beichuan Qianghuang Cultural Industry Corporation, Beichuan Xiuniang Cultural Industry Corporation and Beichuan Shalang Cultural Tourist Corporation. Table 1 lists the information of the enterprises. It could be observed that all of the enterprises are established by the non-craftspeople after the earthquake. The entrepreneurs adopt "enterprise + households" operation model and recruit both full-time and part-time embroiderers. However, those firms reformed the products in different ways. For example, Qianghuang established master studio and Research \& Development department; Xiuniang reformed the products by using techniques of Suzhou embroidery in Qiang embroidery firstly; and Xiuniang brands its product as "Yunyunqiang".

Table 1. Information on Qiang embroidery enterprises in Beichuan

\begin{tabular}{|c|c|c|c|}
\hline & Beichuan Qianghuang & Beichuan Xiuniang & Beichuan Shalang \\
\hline Found in & 2012 & 2011 & 2009 \\
\hline $\begin{array}{l}\text { Founder } \\
\text { Operation } \\
\text { Model }\end{array}$ & $\begin{array}{l}\text { non craftspeople, outsiders } \\
\text { enterprise }+ \text { processing base }+ \\
\text { households }\end{array}$ & $\begin{array}{l}\text { non-craftspeople, outsiders } \\
\text { enterprise }+ \text { households }\end{array}$ & $\begin{array}{l}\text { non-craftspeople, returnee } \\
\text { enterprise }+ \text { households }\end{array}$ \\
\hline Employees & $\begin{array}{l}60 \text { full-time embroiderers; more } \\
\text { than } 1000 \text { part-time } \\
\text { embroiderers working at home }\end{array}$ & $\begin{array}{l}80 \text { full-time embroiderers; more } \\
\text { than } 500 \text { part-time embroiderers. }\end{array}$ & $\begin{array}{l}32 \text { full-time embroiderers; more } \\
\text { than } 400 \text { part-time } \\
\text { embroiderers. }\end{array}$ \\
\hline Customers & $\begin{array}{l}\text { government, entrepreneurs, } \\
\text { overseas and domestic visitors }\end{array}$ & government, domestic visitors & $\begin{array}{l}\text { philanthropist, NGO, domestic } \\
\text { visitors, locals }\end{array}$ \\
\hline Features & $\begin{array}{l}\text { Training System: Junior- } \\
\text { Intermediate-Senior- } \\
\text { Technician-Master }\end{array}$ & $\begin{array}{l}\text { "Reformer":use techniques of } \\
\text { Suzhou embroidery in Qiang } \\
\text { embroidery; }\end{array}$ & $\begin{array}{l}\text { Brand "Yunyunqiang" "Qiang } \\
\text { Culture Museum" }\end{array}$ \\
\hline
\end{tabular}

\section{Impacts of Tourism on the Embroidery: from the Perspective of Supply Side}

\subsection{Pre-earthquake Products and After-earthquake Products}

After the earthquake, embroidery industry developed fast and had boosted employment of women in Beichuan. All of the elites agreed that the embroidery handicraft has changed from daily living goods to the tourism commodity. Table 2 lists the changes in design, base color, backer, figure, thread and utility. Producing and selling innovated product could yield great profits. Sometimes the sale price of a piece of handicraft product is even ten times as the wage of embroiderers. For example, a piece of tapestry priced 400,000 RMB could be completed within three months by six professional embroiderers whose salary is about $3000 \mathrm{RMB} /$ per month each.

Table 2. Changes in Qiang embroidery handicrafts

\begin{tabular}{lll}
\hline Items & pre-earthquake & after-earthquake \\
\hline Design & picture in mind & base on patterns designed before \\
Base color & black, blue, white & black was replaced by diversified colors \\
Backer & native cloth or cotton fabric & diversified cloth \\
Figure & Qiang daily life, natural scenes, plants & peony, leaders, earthquake relief and Ancient \\
& and animals & Tea-Horse Road that popular to tourists \\
Thread & cotton thread, linen thread and yarn & silk thread and yarn \\
Utility & living goods, personal articles or gifts & transform to commodity \\
\hline
\end{tabular}

Data source: interview 
Figure 3 summarizes the producing and selling processes of the current embroidery industry. Supported by government and banks, the entrepreneurs recruit designers and technicians to produce the embroidery. During the production process, the enterprises provide craftspeople with raw materials, techniques, and money, predict the trends and improve the products. The respondents noticed that previously local residents sold embroidery handicrafts to visitors directly in Qiang village, but now all embroidery products concentrated in Banaqia Shopping Street. All of the firms focus on marketing the products through its' own shops in Beichuan. As a result, enterprises have become a bridge that links local craftspeople with external market through selling to visitors directly, gathering feedback and reforming design of products.

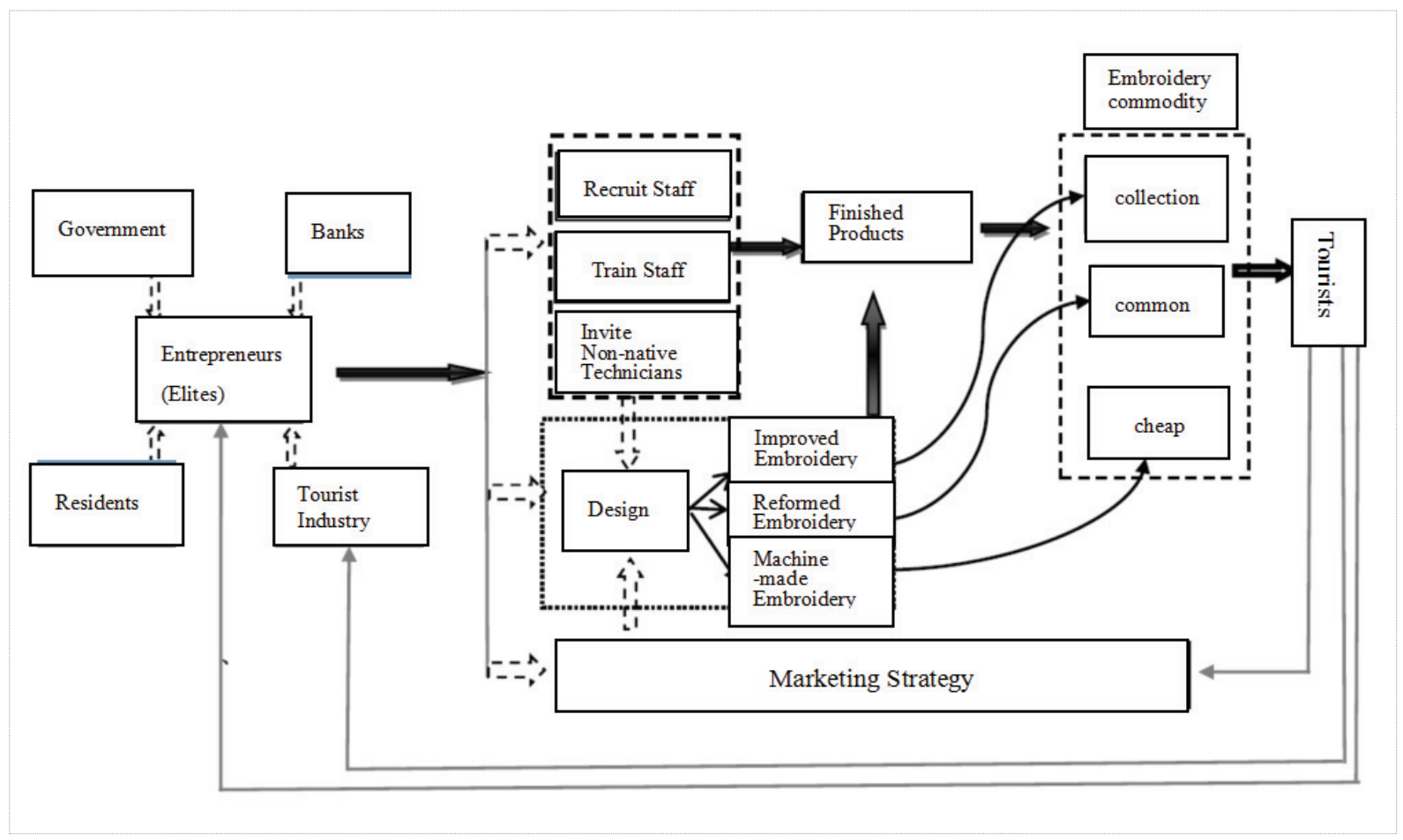

Figure 3. Produce and sales processes of Qiang embroidery enterprises in Beichuan

The owners and staffs of embroidery enterprises noticed a change of customers. Before 2013, the primary customers were government and company, while the consumption of expensive handicraft products relies heavily on government procurement. As a kind of donation, tourists purchased the innovated and improved crafts without paying attention to price, design or usage. After 2013, the proportion of government and company consumption decreased from $80 \%-60 \%$ to $60-40 \%$. Also, the tourists prefer to buy machine-made products which are cheaper the man-made items. These changes have brought challenges to the industry. The firms have to change the products style and distribution channel to meet the tourists' demand. Before 2013, for example, Beichuan Qianghuang mainly produced innovated and improved products, and sold the products to government, VIP clients, or philanthropists. After 2013, this firm strated to develop common products, and carried out promotions in the tourism area.

However, respondents have different opinions on the effect of tourism on embroidery industry. Government officers and staffs indicate that tourism was growing rapidly, but had little influence on embroidery industry. They argued that the handicraft industry after disaster is government-leading project. Oppositely, owners and staffs of embroidery enterprises agreed that tourism have influenced embroidery industry in Beichuan. Such as the owner of one enterprise said that the tourism is reshaping the craft industry now. He predicted that Beichuan Qiang embroidery industry would get into a dilemma, if could not solve the problems related to profit distribution, promotion channel and product price are effectively in the next few years. 


\section{$6 \quad$ Tourist Perception on Qiang Embroidery Handicrafts}

\subsection{Transport Method, Length of Stay and Budget of the Tourists}

Table 3 shows transport methods, length of stay and budget of the tourists, according to the questionnaire survey. It could be observed that $91 \%$ of the tourists are individual tourists, while only $9 \%$ of tourists bought package tour. Beichuan Qiang Tourist Area is a typical one-day-trip destination, due to $82 \%$ of the respondents stayed less than 24 hours. The estimated expenditures of respondents were relatively low: $33 \%$ of the respondents expanded less than 100 RMB; $38 \%$ planned to spend 100 to 300 RMB, $5 \%$ chose 800 to 2000 RMB. Only one percent of visitors predict to consume more than 2000 RMB. Some tourists said they had no expense except fuel and toll cost. Some also said that they did not know the local products because they had no chance to communicate with the local.

Table 3. Tourists transport methods, length of stay and budget

\begin{tabular}{lc|lc}
\hline Duration & Percentage & Expenditure(RMB) & Percentage \\
\hline Less than 3 hours & $7 \%$ & Less than 100 & $33 \%$ \\
Half day & $40 \%$ & $100 \sim 300$ & $38 \%$ \\
One day & $35 \%$ & $300 \sim 800$ & $14 \%$ \\
One to two days & $13 \%$ & $800 \sim 2000$ & $5 \%$ \\
More than two days & $5 \%$ & More than 2000 & $1 \%$ \\
No Response & 0 & No Response & $9 \%$ \\
Total & $100 \%$ & Total & $100 \%$ \\
\hline
\end{tabular}

Source: Tourists questionnaire survey

\subsection{Motivation to Visit Beichuan}

According to survey, $75 \%$ of travelers' motivation are related to earthquake such as visiting the Former County Earthquake Relic, see the disaster site closely, learning knowledge about earthquake prevention, studying reconstruction process, or receiving patriotic education. Meanwhile, the motivation of more than $12 \%$ of visitors is experience Qiang ethnic culture. Vast traditional Qiang architecture elements were used in building of New Beichuan, and culture activities were hold in scenic area from time to time. It can be seen that Beichuan Former County Earthquake Relic is the key attraction of Beichuan, while the Qiang culture has become one of the tourist attraction.

\subsection{Perception of Visitors on Qiang Embroidery}

Overall, Qiang embroidery could represent tourist destination image of Beichuan to some degree. The questionnaire survey shows that $40 \%$ of respondents believed that Qiang embroidery could represent the image of new Beichuan. Nearly half $(49 \%)$ of the respondents could not be sure and remaining $11 \%$ said "No".

Approximately two thirds of respondents were satisfied with the quality and variety of tourist commodities in Beichuan. More than one quarter (28\%) bought tourist commodities including machine-made Qiang embroidery products, while only couple of respondents purchased hand-made ones. Reasons as follows: (1) the gap between high price of handicrafts and low predicted expenditure; (2) respondents' knowing little about Qiang embroidery handicrafts. (3) Staying time in Banaqia Shopping Street is short while products sold in main scenic spots are machine-made (hand-made embroidery stores are here while machine-made products are predominant in other scenic spots).

\section{$7 \quad$ Discussion and conclusion}

This paper investigates the impacts of tourism on traditional Qiang embroidery handcraft in Beichuan after the "5.12" Earthquake, as well as studies how Qiang cultural element changed the image of Beichuan 
for a natural disaster tourism site to ethnic tourism destination. The experience of Beichuan shows that producing and selling crafts is one of significant sources of income, improving employment, eradicating poverty, leading to empowerment, developing economic level, and generating more opportunities for local.

The study results confirmed that tourism industry has promoted the Qiang embroidery industry. In the process of reconstruction, Qiang embroidery has changed from local residents' daily item to tourism handicraft and art collections. After the earthquake, some outsiders set up cultural enterprises to produce and sale the embroidery handcraft in Beichuan. In the first five years after the earthquake, the entrepreneurs refer to produce innovated or improved products to meet the demand of government, VIP clients, or philanthropists. After 2013, the agents started to develop common products, as the buying power of government and enterprises decreased and tourists become main buyers of the embroidery. The implication of this change is obvious: tourist demand is the main the force that guides handicraft innovation and diversification (Cohen, 1993, Xu et. al., 2014) even in the disaster site.

Souvenirs values are interpreted by tourists in relation to their utility, their meanings and the memories they represent (Paraskevaidis \& Andriotis, 2015). In the first five years after the earthquake, tourists bought expensive embroidery handcrafts for charity. As time goes by, the tourists become rational and pay more attention to price and utility. Thus, only couple of respondents purchased hand-made embroidery crafts. Short staying time, relatively low estimated expenditure and knowing little about Qiang embroidery resulted in low sales of the embroidery crafts. Due to the tourists prefer to buy mass-produced souvenirs (Hu \& Yu, 2007), thus machine-made embroidery products from outside become the dominant souvenirs in scenic spots.

Questionnaire survey shows that earthquake ruins and muses building are the key attractions of Beichuan. However, $12 \%$ of the respondents' motivations are related to Qiang culture. Furthermore, $40 \%$ of them believed that Qiang embroidery could represent a new image of Beichuan on certain degree. The dark tourism products really lie along a following spectrum of intensity from darkest to dark then to light and lightest, depending upon political influence, time-scale from the disaster, tourism develop level, authentic, education or entertainment interpretation styles (Stone, 2006).Thus, merged with the ethic culture elements, the Beichuan may be conceivably lighter than before.

This study demonstrates that special after-quake environment and policies fostered a group of Qiang embroidery enterprises run by non-craftspeople. The enterprises provide craftspeople with raw materials, money, techniques, and keep the authority features of their products, at least, in three aspects: containing handmade embroidery, embroidery work did in Beichuan, and craftspeople are Qiang population. On the other hand, the enterprise model reduces communication opportunities between tourists and the local, which is likely to weaken participation and enthusiasm of craftspeople in some way. In order to realize the sustainable development, government should empower local people right of engaging in controlling materials, capital, profits and benefit distribution in the industry. Also, the higher quality and authenticity of embroiderers' product should be emphasized so that tourists can see the reason for the higher price of the local hand-made products.

Acknowledgement. The study is supported by the National Natural Science Foundation of China (51508484), Sichuan Social Science Planning Foundation (SC17TJ009), Sichuan Social Science Major Research Center Foundation for County Economic (XY2017019), the young talent program by State Ethnic Affairs Commission, the Education Reform Funding of Southwest University for Nationalities (2015ZD03).

\section{References}

1. Biran A, Poria Y, Oren G. 2011. Sought Experiences at Dark Heritage Sites. Annals of Tourism Research 38(3): 820-841.

2. Cohen E. 1993.The heterogenization of a tourist art. Annals of Tourism Research 20(1), 138-163.

3. Funck, C., (2015). Rebuild, Remember, Prepare: Messages of the 1995 Great Hanshin-Awaji Earthquake. Asia Pacific World 2014,5(2).

4. Hu B., Yu, H. 2007. Segmentation by craft selection criteria and shopping involvement. Tourism Management 28(4), 1079-1092. 
5. Littrell A.M., Anderson FL., Brown J.P. 1993. What makes a craft souvenir authentic? Annals of Tourism Research 20 (1), 197-215.

6. Master Plan of Tourism Development for Beichuan Qiang Autonomous County, Sichuan Province, China. Shanghai Academy of Social Sciences 2009

7. Lennon JJ, Foley M. 2000. Dark tourism: The Attraction of Death and Disaster. Continuum: New York.

8. Paraskevaidis P., Andriotis K. 2015. Values of souvenirs as commodities. Tourism Management, 1-10.

9. Seaton T. (2009)Purposeful Otherness: Approaches to the management of Thanatourism. In: Sharpley R, Stone PR (ed.). The darker side of travel: The theory and practice of dark tourism. Channel View Publications: Bristol, 2009, 75-108

10. Smith M. 2009. Issues in Cultural Tourism Studies, London : Routledge .

11. Swanson K. 2004. Tourists' and retailers' perceptions of souvenirs. Journal of Vacation Marketing, 10(4), 363-377.

12. Swanson, K. K., Timothy, D. J. 2012. Souvenirs: Icons of meaning, commercialization and commoditization. Tourism Management 33(3), 489-499.

13. Stone P. 2006. A dark tourism spectrum: Towards a typology of death and macabre related tourist sites, attractions and exhibitions. Tourism 54(2): 145-160.

14. Strange C, Kempa M. 2003. Shades of dark tourism: Alcatraz and Robben Island. Annals of Tourism Research 30(2): 386-405.

15. Winter C. 2009. Tourism, social memory and the Great War. Annals of Tourism Research 36(4): 607-626.

16. Wu C., Funck C., Hayashi Y. 2014. The Impact of Host Community on Destination (re)branding: A Case Study of Hiroshima. International Journal of Tourism Research 16(6), 546-555.

17. Xu H., Zhang T., Shi N. 2014. The Impact of Cultural Tourism on the Innovation of Ethnic Handicraft Production in Dali, China. Asia Pacific World, 5(2), 82-100.

18. Yang W, Wang D, Cheng G. 2011. Reconstruction strategies after the Wenchuan Earthquake in Sichuan, China. Tourism Management 32(4): 949-956. 